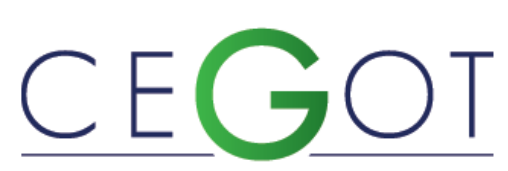

Centro de Estudos de Geografia e Ordenamento do Território
Geografia e Ordenamento do Território, Revista Eletrónica Centro de Estudos de Geografia e Ordenamento do Território http://cegot.org

GUINOTE, JOSÉ

Rua Mário Cesariny nำ-1ํㅡ, 6300-031 Lisboa, Portugal Josecarlos.guinote@gmail.com

\title{
A afetação social das mais-valias no planeamento urbano - a nova lei de solos em Portugal
}

Social allocation of plus values in urban planning - the new land policy law in Portugal

Referência: Guinote, José (2019). A afetação social das mais-valias no planeamento urbano - a nova lei de solos em Portugal. Revista de Geografia e Ordenamento do Território (GOT), n. ${ }^{\circ} 17$ (junho). Centro de Estudos de Geografia e Ordenamento do Território, p. 93-121, dx.doi.org/10.17127/got/2019.17.005

\section{RESUMO}

O artigo apresenta uma proposta de afetação social das mais-valias urbanísticas. Partimos do que estabelece a Lei $\mathrm{n} \cong 31 / 2014$ - LBGPPSOTU - para clarificar aquilo que deve ser entendido como afetação social das mais-valias. Desenvolve-se uma proposta de alteração tendo em vista concretizar os objetivos de justiça social que a lei visa atingir. Discute-se a alteração no quadro da relação que o Estado estabelece com o Mercado em torno do desenvolvimento urbano e em particular na relação entre o Estado regulador e o Estado produtor. E ainda se apresenta a aplicação de uma proposta de financiamento da Política de Habitação. Esta pesquisa baseia-se numa investigação conduzida no concelho de Alcochete.

Palavras-chave: Política de habitação; Política de Solos; Mais-Valias Urbanística; Equidade; Justiça espacial

\section{ABSTRACT}

The article presents a proposal of social allocation of Plus Values. We start by examining what Law No. 31/2014 - LBGPPSOTU - establishes to clarify what should be understood by social allocation of plus values. A proposal for an amendment is developed aiming at putting into practice the objective of social justice that the Law intends to achieve. It is discussed the change in the framework of the relationship that the State establishes as regards urban development and particularly in the relationship between the regulatory State and the State as a producer. A proposal to finance the Housing Policy is also presented. This study is based on a research carried out in the municipality of Alcochete.

Keywords: Housing Policy; Land Policy; Plus Values; Equity; Spatial Justice 


\section{Introdução}

Em 30 de Maio de 2014 o Governo fez publicar em Diário da República a nova Lei de Bases Gerais da Politica Pública de Solos, do Ordenamento do Território e do Urbanismo ${ }^{1}$. A importância da Política de Solos fora retomada quinze anos antes com a Lei de Bases da Política de Ordenamento do Território e de Urbanismo - Lei 48/98 e o Regime Jurídico dos Instrumentos de Gestão Territorial, aprovado em 1999 com o Decreto-Lei 380/99. A revisão da lei de solos passou a ser um imperativo resultante da aplicação do art. 16 da Lei de Bases. Aí determinava-se o dever de a Administração Pública proceder à execução coordenada e programada dos instrumentos de planeamento territorial, recorrendo aos meios de política de solos que viessem a ser estabelecidos na lei. O Decreto-Lei no 380/99 estabeleceu, no seu preâmbulo, a exigência de regulamentação complementar, no domínio da política de solos e dos instrumentos de transformação da estrutura fundiária. Seguiu-se um longo hiato temporal interrompido pela aprovação da LBGPPSOTU em 2014.

A revisão da Lei gerara importantes expectativas. No entanto, ainda durante a sua elaboração, diferentes entidades e especialistas consultados durante o processo de audição pública sobre a proposta de Lei $^{2}$, emitiram pareceres manifestando reservas sobre diferentes aspetos. Entre outras posições, destacamos a do Conselho Nacional do Ambiente e do Desenvolvimento Sustentável (CNADS) sobre a afetação social das mais-valias e a da Ordem dos Arquitetos -OA- sobre a articulação da Política de Solos com a Política de Habitação.

Parece evidente, consultados os documentos disponíveis, nomeadamente os Relatórios de Progresso e as Notas Técnicas emitidas pela Direção Geral Ordenamento do Território e Desenvolvimento Urbano - DGOTDU - durante o processo de elaboração da Lei, que aspetos considerados inicialmente como estratégicos foram ignorados na versão final ou tratados de forma a suscitar um conjunto acrescido de ineficácias.

Neste artigo propomo-nos refletir sobre a afetação social das mais-valias. Não tendo a Lei esclarecido o conceito, nem fixado a percentagem da mais-valia gerada a afetar

\footnotetext{
${ }^{1}$ Lei no 31/2014 publicada no Diário da República, 1a série - № 104 de 30 de Maio de 2014, conhecida pela sigla LBGPPSOTU.

2 Audições que decorreram no âmbito da Assembleia da República que podem ser consultadas em https://www.parlamento.pt/ActividadeParlamentar/Paginas/Detalhelniciativa.aspx?BID=38024
} 
socialmente, os objetivos perseguidos ficaram longe de poder ser alcançados. Apresentamos uma proposta de clarificação da afetação social das mais-valias, não apenas qualitativa mas também quantitativamente. Recorremos aos resultados de uma investigação que realizámos no concelho de Alcochete $^{3}$ para ilustrar os efeitos da aplicação da proposta aqui apresentada. Essa investigação permitiu-nos mapear a geração de maisvalias entre 1997 e 2015 no território do concelho.

\section{Enquadramento da revisão da Lei de Solos}

Durante o período que medeia entre 1999 e 2014, muito marcado pela crise do sub-prime no ano de 2008, emergiu um debate internacional sobre a necessidade de uma efetiva regulação do desenvolvimento urbano e em particular sobre a necessidade de repensarmos a forma como o Estado regula, ou não, a utilização do uso do solo (Needham, 2006). A rápida transformação de vastos territórios com o acréscimo da urbanização, e um conjunto de desigualdades e injustiças espaciais a ela associadas, colocou na ordem do dia a discussão sobre a necessidade de regular esse desenvolvimento e conduziu a uma discussão sobre o papel a desempenhar pelo Estado nessa regulação. A mudança que se verificou ao longo das últimas décadas, durante a qual os sistemas políticos dominantes, particularmente europeus, evoluíram da velha social-democracia para o neoliberalismo, foi acompanhada por alterações profundas nas políticas públicas com expressão no território. Essas alterações consagraram o predomínio do Mercado e a anulação do Estado produtor, substituído pelo Estado regulador, características fundamentais do neoliberalismo (Fainstein, 2010); Harvey, 2008); Soja, 2010).

O ano de 2008, com a crise do sub-prime, abalou as fundações do modelo neoliberal vigente. Questionou-se então a eficácia e a eficiência da atuação do Estado Regulador. 0 debate foi dominado pelas questões da eficácia e da eficiência e ignoram-se as questões da justiça e da equidade, cuja negação aparecera como a expressão, muitas vezes chocante, da

\footnotetext{
${ }^{3}$ Investigação realizada para a obtenção do grau de Doutor em Urbanismo, na Universidade de Lisboa (UL), cujo título é: "Desenvolvimento Urbano, Justiça Espacial e o Papel da Política de Solos e de Habitação. O caso do Concelho de Alcochete na AML."
} 
crise então vivida (Needham, 2006); Fainstein, 2010). Na realidade convocou-se para o debate então travado o Estado regulador, não para assumir as suas responsabilidades pelo não cumprimento dos objetivos sociais de que ele era o garante, mas para assumir como suas as responsabilidades pelo mau funcionamento dos Mercados.

Apesar da grande crise que abalou as economias dos países de mercado livre ter tido a sua origem associada ao desenvolvimento urbano, instâncias internacionais, como o Banco Mundial (BM), insistiram em minimizar a importância do processo de urbanização no contexto da economia mundial. O ambiente construído, a habitação e o processo de urbanização foram quase sempre olhados como questões menores no contexto da grande economia. Apenas em 2009, pela primeira vez na história, o Relatório do BM (WDR, 2009) sobre o desenvolvimento prestou atenção às questões relacionadas com o processo de urbanização. Harvey (2012:p.28) escreveu, a propósito desse Relatório ${ }^{4}$, o seguinte:

“(...) the authors were actually out to show how the application of the usual nostrum of neoliberal economics to urban affairs (like getting the state out of the business of any serious regulation of land and property markets and minimizing the interventions of urban, regional and spatial planning in the name of social justice and regional equality) was the best way to augment economic growth (in other words, capital accumulation)" ${ }^{5}$

O Relatório, apesar da crise já então instalada na economia mundial, faz ainda eco de uma visão que associa a prosperidade futura à observância dos princípios fundadores do neoliberalismo, que conduziram à situação existente. O Relatório enfatiza a importância de uma efectiva proteção do direito de propriedade e alerta para os perigos associados a uma regulamentação restritiva do uso do solo e da edificabilidade. Estabelece mesmo uma relação direta entre a regulamentação do uso do solo e a escassez de oferta de habitação acessível. Por outro lado defende o acesso à habitação através da aquisição com recurso ao crédito, valorizando o reconhecimento social das famílias que são proprietárias das suas habitações.

Encontramos, no Relatório, a defesa da anulação da intervenção do Estado como garante de prosperidade. Nesta fase o foco passou a ser a redução, ao mínimo possível, do papel do

\footnotetext{
${ }^{4}$ World Development Report, 2009. Reshaping Economic Geography. Washington DC. WorldBank. 2009.

5 "Os autores estão, na verdade, a justificar como a aplicação da prática usual da economia neoliberal aos assuntos urbanos (como tirar o Estado do negócio de qualquer regulamentação séria dos mercados de solos e imobiliários e minimizar as intervenções de planeamento urbano, regional e espacial em nome de justiça social e da igualdade regional) foi a melhor maneira de aumentar o crescimento económico (ou seja, a acumulação de capital)".
} 
Estado regulador. O que se defende é a existência de uma não regulação - a minimização do planeamento e da regulamentação do uso do solo - como fator de prosperidade.

Uma década passada, as mudanças realizadas nas estruturas de regulação manifestaram-se insuficientes. No limite o que se assumiu foi que as estruturas de regulação tinham muitas vezes agido por omissão, deixando o Mercado atuar livremente. Mas essa constatação não determinou que as alterações concretizadas no funcionamento das estruturas de regulação fossem de molde a torná-las capazes de prevenir as crises determinadas pelas falhas na sua atuação.

Há dois debates que se travam em volta da Política de Solos e que devemos aqui referir, ainda que de forma breve. Quando falamos de Política de Solos estamos a referir-nos às leis que fazemos para determinar a forma como usamos o solo, o que, na designação de Needham (2012), pode ser associado quer ao Land-Use Planning, quer ao Spatial Planning, quer ainda ao Town and Country Planning. O primeiro debate visa arbitrar o conflito entre o planeamento do uso do solo, enquanto atividade pública, e os direitos de propriedade, exercidos livremente no mercado livre. Participam neste debate, em campos opostos, os que defendem os direitos inegociáveis da propriedade privada do solo (Nozick (1974), e os que defendem o direito do Estado a estabelecer os meios que permitam alcançar os seus objetivos sociais (Booth, 2012); Needham, (2006); Fainstein, (2010), incluindo o direito de planear o uso do solo. Assume particular relevância a relação entre o planeamento do uso do solo e os direitos de propriedade (Needham, 2006) e, em particular, a própria legitimidade do Estado parar planear o seu uso. A orientação dominante em termos globais, mas com expressão no caso português, tem sido a favor de uma menor intervenção do Estado, invocando uma perda de competitividade dos territórios, associada ao carácter burocrático da intervenção pública.

O segundo debate trava-se no campo dos que defendem a intervenção do Estado. Tem a ver com o posicionamento atribuído ao Estado no processo de urbanização. Há duas posições aparentemente incomunicáveis: o Estado produtor/proprietário de solo urbano versus o Estado regulador da classificação/utilização desse mesmo solo. Há autores (Fainstein, 2012) que entendem ser a posse pública do solo a condição sine qua non para introduzirmos equidade no processo de desenvolvimento urbano. Outros defendem que através da socialização das mais-valias o Estado consegue esse objetivo sem se envolver na posse 
pública do solo. Needham (2006) abordou a redistribuição dos recursos e dos seus efeitos sócio culturais, associado à questão da equidade das políticas públicas na regulação das externalidades. A questão da regulação das externalidades remete-nos para a discussão em torno da eficiência na gestão de recursos escassos. Mas acrescenta uma nova perspetiva que complementa essa abordagem: a dimensão da equidade. É esse objetivo da equidade, presente nas políticas públicas com expressão urbana, que possibilita, ou não, impedir que as externalidades agravem as condições de desigualdade e de injustiça já existentes na sociedade. Needham (2006) recorre a Harvey (2000) para questionar o ponto de vista dos defensores do mercado livre e a defesa da não intervenção pública, ou melhor, a defesa de que a intervenção pública não deve realizar-se através da redistribuição dos recursos mas, tão somente, caso o mercado não seja eficaz, realizando essa redistribuição através do sistema de impostos. Recorrendo a um velho adágio referido por Harvey (2000:p.76) : "Nothing is more unequal than the equal treatment of unequal's" ${ }^{6}$, Needham conclui o seguinte:

\footnotetext{
"Trying to achieve allocative efficiency by letting the market treat unequals equally produce unequal results. It might be better first to reduce the inequality, than let the market treat everyone equally." $\left(2006\right.$, p.66) ${ }^{7}$
}

Se recorrermos a Fainstein (2010) e analisarmos as suas propostas para alcançar o objetivo da equidade nas políticas públicas com expressão urbana, verificamos que entre elas se destacam as preocupações com a habitação para as classes de menores rendimentos. Não se trata apenas de defender uma percentagem de novas habitações a custos acessíveis para as classes de menor rendimento em todos os novos desenvolvimentos urbanos, mas também de defender a impossibilidade do stock desse tipo de habitação poder diminuir. Acresce a estas duas dimensões o facto de apenas com consentimento dos moradores se poder admitir a relocalização espacial desse tipo de habitação. Trata-se de evitar a concretização do mecanismo da segregação espacial que, através dos fenómenos da especulação fundiária, tende a libertar os solos urbanos mais valorizados das classes menos afluentes, canalizando-os para a especulação imobiliária e afastando os seus moradores originais para as periferias.

\footnotetext{
6 "Nada é mais desigual do que o igual tratamento dos desiguais". TdP.

7 "Tentar alcançar uma alocação de recursos eficiente deixando o mercado tratar igualmente os desiguais produz resultados desiguais. Seria melhor em primeiro lugar reduzir a desigualdade, do que deixar o marcado tratar toda a gente igualmente". TdP.
} 
A estes aspetos Fainstein soma a preocupação com a acessibilidade. Chama a atenção para as portagens urbanas ou para outras taxas que incidam sobre a mobilidade urbana. Estas taxas penalizam as pessoas que empurradas para as periferias pelas regras do mercado imobiliário - só conseguem encontrar habitação a preços acessíveis muito afastados do centro -são depois obrigadas a deslocar-se para o centro para aí trabalharem. Neste caso qualquer pequena alteração nos custos da acessibilidade tem efeitos imediatos na solvência das famílias. A equidade das políticas públicas e a redistribuição dos recursos obrigam-nos a olhar para a política de solos de uma forma integrada com a política de habitação. De certo modo o objetivo da equidade nas políticas públicas urbanas obriga-nos a olhar para uma Política das Cidades que terá como eixos fundamentais a Política de Solos, a Política de Habitação e uma Política de Emprego (Chaline, 2006/1997). Grande parte da rigidez do mercado do trabalho, em particular aquela relacionada com a mobilidade do fator trabalho, está muito associada ao elevado endividamento provocado pela exclusividade do acesso à habitação através da aquisição no mercado livre ${ }^{8}$.

O carácter obrigatório da revisão da lei de solos não conferiu celeridade ao processo. Apenas no XVII Governo Constitucional ${ }^{9}$ o SEOTC, João Ferrão, se referiu à necessidade de avançar com a revisão da Lei de Solos. Foi a primeira vez, em termos políticos e institucionais, que um responsável político abordou a necessidade de serem controladas as mais-valias associadas à mudança de uso do solo (de rústico para urbano).

Apesar dessa vontade política, e do que o programa do Governo sobre ela determinava, não aconteceram alterações até ao final da legislatura. Recorde-se que este debate ocorreu no contexto de uma discussão então muito presente na sociedade portuguesa que associava o processo de urbanização em curso, com a captura das mais-valias da urbanização pelos particulares e com os níveis crescentes de corrupção na sociedade portuguesa. Então assumiu particular destaque a divulgação dos trabalhos sobre a mudança de uso dos solos e a transformação de solos rústicos em solos urbanos (Caetano, Carrão e Painho, 2005). Essa divulgação ocorreu no final de um longo período que ficou marcado por uma importante

\footnotetext{
${ }^{8}$ Este fenómeno é particularmente sentido em Portugal, embora pouco discutido e compreendido.

${ }^{9} \mathrm{O}$ XVII Governo Constitucional tomou posse em 12.03.2005 e cessou funções em 26.10.2009, no final da legislatura. Foi liderado por José Sócrates e teve como Ministro do Ambiente, Francisco Nunes Correia, sendo Secretário de Estado do Ordenamento do Território e das Cidades, João Ferrão.
} 
expansão dos perímetros urbanos que visava responder a uma procura de solos urbanizáveis que se veio a revelar sobredimensionada.

João Cravinho, deputado eleito pelo Partido Socialista, liderou, numa primeira fase, as iniciativas políticas de luta contra a corrupção, então muito centradas no urbanismo e na captura pelos privados das mais-valias, que não encontraram eco por parte do Governo. Já no final da legislatura, em Agosto de 2008, João Ferrão ${ }^{10}$ anunciava que o Governo iria avançar com a submissão de uma proposta ainda nessa legislatura. Na mesma altura referia que Portugal se destacava "entre os países da União Europeia na voracidade de transformação de solo rural em solo urbano". Como se sabe essa voracidade é potenciada pela possibilidade que lhe está associada de proceder à captura das mais-valias urbanísticas. Só no final da legislatura seguinte - XVIII Governo Constitucional ${ }^{11}$ - se iniciou o processo que iria conduzir a essa revisão.

No primeiro semestre de 2010, doze anos depois da aprovação da Lei de Bases, a DGOTDU iniciou um processo devidamente calendarizado que apontava para a aprovação de uma nova Lei de Solos.

\section{O processo de conceção da lei}

A DGOTDU, no âmbito das funções que lhe foram atribuídas, elaborou um conjunto de Relatórios de Progresso e de Notas Técnicas que são úteis para contextualizarmos a nova Lei. Afirma-se no Relatório de Progresso ${ }^{12}$ de 20-06-2011, que:

“O Programa do XVIII Governo Constitucional prevê no seu Cap. IV (...) sob a epígrafe "Ordenamento do Território e Cidades", o seguinte:

Especial atenção será dada à política de solos, através da aprovação de uma nova lei de solos, que clarifique e regule os direitos e deveres da administração pública e dos cidadãos, em especial dos proprietários e dos outros agentes que intervêm na ocupação, uso e transformação do solo, designadamente para fins produtivos, de urbanização e de edificação.

Em particular, a nova lei dos solos deverá clarificar as relações entre o direito de propriedade e o direito (e dever) de edificar, bem como entre o direito de edificar

\footnotetext{
${ }^{10}$ Citado no Público de 22.08.2008, num trabalho de Jorge Talixa sob o título "Governo hesita sobre alterações à Lei dos Solos".

${ }^{11}$ O XVIII Governo Constitucional tomou posse em 27.10.2009 e apresentou a sua demissão em 23.03.2011. Foi liderado por José Sócrates e teve como Ministra do Ambiente, Lurdes Pássaro.

${ }^{12}$ Preparação do projeto da nova Lei do Solo. Relatório de Progresso. Lisboa, DGOTDU,2011-06-20
} 
e uma repartição transparente, eficiente e justa dos custos de urbanização e das mais-valias resultantes dos processos de infraestruturação, urbanização e edificação,"

Como se percebe por esta citação a revisão da Lei de Solos teria que abordar obrigatoriamente a questão das mais-valias e uma clarificação das relações entre o direito de propriedade e o direito de edificar. Deixava de fora as relações entre o direito de propriedade e o direito de urbanizar, questão importante no processo de geração das maisvalias e nos mecanismos associados à sua captura ou socialização.

A DGOTDU emitira em 11.02.2011, ainda no âmbito do XVIII Governo Constitucional, uma Nota Técnica1 que esclarece a "Focagem da Nova Lei do Solo", reflete sobre os "Problemas Fundamentais" e estabelece os "Resultados a Atingir com a Lei". Na análise dos "Problemas Fundamentais" que determinavam a ineficácia dos Sistema de Gestão Territorial eram identificados como fatores críticos a desarticulação entre os mecanismos do mercado imobiliário, da fiscalidade e do planeamento territorial e a desarticulação entre os instrumentos de política de solos. Os resultados a atingir com a nova lei eram depois elencados e sintetizados em quatro objetivos: regular a formação da renda fundiária; regular a formação e a distribuição das mais-valias fundiárias; promover uma gestão territorial mais eficaz e proactiva e fazer convergir os diversos instrumentos de política fundiária. Quanto aos dois primeiros objetivos, fundamentais para qualquer Lei de Solos, a Nota Técnica ${ }^{13}$ acrescentava o seguinte:

\begin{abstract}
"Regular a formação e a distribuição de mais-valias fundiárias tendo em conta os direitos e deveres associados aos diferentes estatutos do solo (direitos e deveres dos cidadãos em geral, dos proprietários e do Estado, apropriação pública das mais valias decorrentes dos investimentos públicos em infraestruturas territoriais e urbanas e de atos administrativos, remuneração de serviços ambientais, etc.);"
\end{abstract}

Há aqui a assunção de que a Administração Pública desempenha um papel neste processo de formação da renda fundiária e na formação das mais-valias, sendo por isso legitimo que atue no sentido de regular quer os processos da sua formação quer os processos da sua captura. Nesta "Nota Técnica" merece destaque a parte dedicada ao direito de propriedade. Refere-se que a lei opera no quadro do OTU e não a partir de uma tentativa de delimitação abstrata do direito de propriedade. Propondo-se, em função disso, um esquema conceptual que apontava para uma importante leitura do direito de urbanizar enquanto direito público, embora passível de ser concedido. Esta conceptualização, a ser seguida posteriormente,

\footnotetext{
${ }^{13}$ Contributo para a definição de âmbito da nova lei do solo. Painel de Orientação Técnica - Nota
} Técnica1/DGOTDU/LdS. P.2 
determinaria importantes alterações quanto ao envolvimento da Administração Pública e dos Privados nos mecanismos que determinam o inicio do processo de urbanização.

No seguimento dos trabalhos a DGOTDU, na sua "Nota Técnica2" de 12.04.2011, dedicada a fazer a síntese das ideias fundamentais resultantes do debate sobre a necessidade de controlo da formação do valor do solo, da apropriação da renda fundiária e da definição do estatuto jurídico do solo, estabelecia, sobre o "Controlo da formação das rendas fundiárias e da sua apropriação" ${ }^{14}$, o seguinte:

“O controlo da formação das rendas fundiárias e da sua apropriação é a questão chave de que depende a efetiva capacidade de aplicação dos IGT, de acordo com os objetivos e no respeito pelos princípios estabelecidos na LBPOTU, na LBA, na ENDS e nos demais documentos estratégicos fundamentais que orientam o nosso desenvolvimento territorial".

Acrescentando-se de seguida que importa,

"contrariar as tendências meramente especulativas que promovem a criação de diferenciais de valor do solo em função de simples expectativas subjetivas ou em função da ação unilateral da administração, sem que os proprietários tenham realizado qualquer investimento produtivo no sentido da concretização do aproveitamento dos terrenos de que são titulares de acordo com os objetivos de desenvolvimento territorial e os regimes de uso do solo estabelecidos nos IGT".

Pretendia-se quantificar o incremento do valor do solo aquando da passagem de solo rústico a solo urbanizável e do solo urbanizável a solo de urbanização programada, reconhecendo-se que nesta passagem o mérito do proprietário é nulo, tudo dependendo da iniciativa da Administração Pública. Esta quantificação serviria de base para a tributação das mais-valias e para a determinação do valor da expropriação.

Na Nota Técnica $3^{15}$, elaborada em 20.06.2011, foi abordada a formação das mais-valias e a valoração do solo para efeitos de expropriação. Reconhecia-se que a questão mais crítica colocava-se :

\footnotetext{
"em relação ao solo sobre o qual possam incidir expectativas de urbanização. Este solo pode ser o que se encontra na imediação dos perímetros urbanos, pode ser solo sobre o qual incide algum projeto de investimento imobiliário, ou pode ser solo incluído no perímetro urbano, embora não programado. Neste último caso, o valor de mercado já incluirá pelo menos uma parte da mais-valia pura que resulta da anterior classificação como urbanizável."
}

A opção então defendida não tinha uma base tributária, situando-se no âmbito dos modelos de compensação urbanística. Apontava-se para a criação de uma Bolsa de Terrenos a

\footnotetext{
${ }^{14}$ Contributo para a definição de âmbito da nova lei do solo. Painel de Orientação Técnica - Nota Técnica2/DGOTDU/LdS. p.6

${ }^{15}$ Contributo para a definição de âmbito da nova lei do solo. Painel de Orientação Técnica - Nota Técnica3/DGOTDU/LdS. P.9
} 
integrar o Património Público Municipal como compensação pela mais-valia apropriada pelo proprietário/promotor. Quanto à valoração do solo para efeitos de expropriação reconhecia-se o carácter crítico desta questão para o funcionamento do sistema de gestão territorial. O documento trata diferentes situações, nomeadamente o solo rural, o solo urbanizável não programado e o solo urbanizável programado. Esta foi a última Nota Técnica produzida tendo o conjunto dos documentos de apoio produzidos durante esta fase ficado concluído com o Relatório de Progresso de 20.06.2011.

\subsection{A Nova Lei de Bases}

Em outubro de 2013, através do Ministro do Ambiente, Ordenamento do Território e Energia, o Governo apresentou a sua Proposta de Lei de Bases da Política de Solos, de Ordenamento do Território e de Urbanismo ${ }^{16}$.

Chamou então a atenção para a necessidade de a lei significar uma mudança de paradigma que passaria pela flexibilização do planeamento, pelo reforço do Plano Diretor Municipal (PDM) como instrumento estratégico e apontou a reabilitação urbana como o caminho para o desenvolvimento das cidades. Nos termos dessa declaração vincou a ideia de que a rigidez do planeamento seria geradora de perda de investimentos e que a flexibilização poderia evitar essa perda de eficácia do sistema territorial. O objetivo passava por "criar condições de investimento e de competitividade no território" ${ }^{17}$ como afirmou então o Ministro.

A realidade observável da intervenção urbanizadora no território e as preocupações patentes nos documentos de apoio que foram sendo produzidos ao longo do processo legislativo não legitimam, no entanto, esta leitura. A dinâmica associada à classificação de terrenos rústicos em terrenos urbanos, à sua transformação em terrenos urbanizáveis, através da emissão de alvarás de loteamento, e a consequente urbanização, seguida da construção de centenas de milhares de edifícios plurifamiliares, moradias unifamiliares, complexos turísticos, equipamentos públicos de apoio à vida urbana, refletiram-se nas

\footnotetext{
${ }^{16}$ Proposta de Lei № 183/XII.

${ }^{17}$ Ver em http://www.portugal.gov.pt/pt/os-ministerios/ministerio-do-ambiente-ordenamento-do-territorioe-energia/mantenha-se-atualizado/20131009-maote-lei-solos.aspx. AC em 24.12.2013.
} 
condições de acesso ao crédito disponível. O crédito concedido ${ }^{18}$ pelo sistema bancário a particulares tem sido maioritariamente para habitação ${ }^{19}$, enquanto o crédito a sociedades não financeiras se destina sobretudo ao sector da construção e do imobiliário. Em 2007 o peso dos sectores da construção e do imobiliário na captura de crédito atingiu um máximo histórico situando-se em $45,6 \%$ do crédito concedido a sociedades não financeiras. Passados onze anos, em 2016, esse valor regrediu para apenas $27 \%$.

Os aspetos da Nova Lei de Bases que mereceram críticas diversas foram a Clarificação do Regime do Solo, a Afetação Social das Mais-Valias e o chamado Mito do "Plano Único". Neste artigo, como já referimos, tratamos apenas da Afetação Social da Mais-Valia. Uma das principais novidades que a lei propõe é uma articulação entre o ordenamento do território e os instrumentos fiscais que incidem sobre o imobiliário, entendidos como instrumentos de política de solos. Há dois aspetos que devem ser lidos conjugadamente. Por um lado os relacionados com a perequação e, por outro, a afetação das mais-valias originadas pela classificação do solo como urbano. Num capítulo com o sugestivo nome de "Instrumentos equitativos" - art. 64ㅇ a 66 - a Lei parece apontar no sentido da afetação social das maisvalias geradas pela aprovação dos planos territoriais de âmbito intermunicipal ou municipal. No entanto, o conteúdo da lei aprovada suscita diversos reparos. No art. 0660 classificam-se os diferentes tipos de benefícios e encargos. Além da "Distribuição dos benefícios e encargos decorrentes do plano territorial de âmbito intermunicipal ou municipal entre os proprietários fundiários", a nova lei estabelece na alínea a), a afetação social de mais-valias gerais atribuídas pelo plano territorial de âmbito intermunicipal ou municipal. Trata-se de uma proposta coerente com o espírito de uma Lei que reconhece (art. 64ㅇa alínea 6) o seguinte:

\footnotetext{
"Para efeitos do disposto nos números anteriores, os planos territoriais de âmbito intermunicipal ou municipal fundamentam o processo de formação das mais-valias fundiárias e definem os critérios para a sua parametrização e redistribuição"
}

Na verdade a Lei, depois de 2014, passou a assumir que as mais-valias são geradas pelos planos territoriais. É nesse quadro que decorre esta reflexão sobre a afetação social da mais-valia, já que a sua consagração na lei não deixa de suscitar algumas dúvidas. Elas

\footnotetext{
18 Ver APB- Associação Portuguesa de Bancos. Overview do Sistema Bancário. http://www.apb.pt/estudos e publicacoes/overview do sistema bancario portugues/

${ }^{19}$ Entre 2007 e 2016 o crédito para habitação no total do crédito concedido a particulares manteve-se estável, baixando ligeiramente de $82 \%$ para $81 \%$ do crédito concedido. http://www.apb.pt/content/files/Novembro Overview do Sistema Bancrio Portugus PT 2.pdf
} 
podem justificar-se desde logo pela análise do art. 65우 que define quais são os objetivos da redistribuição de benefícios e encargos. Entre os diferentes objetivos elencados não consta qualquer referência à garantia de habitação para as classes de menores rendimentos. Tratase de uma omissão incompreensível numa lei que determina uma afetação social das maisvalias. No entanto é verdade que no art. 20 da lei quando são definidos os fins a que ela se destina não é feita qualquer referência aos objetivos de política pública de habitação. Isso mesmo foi salientado no Parecer da Ordem dos Arquitetos (OA, 2013) ${ }^{20}$, quando referiu o seguinte:

\footnotetext{
“Deveria constar do elenco dos fins da Lei de Bases do Ordenamento do Território e do Urbanismo a habitação, como concretização do direito constitucional estabelecido no n.o 1 do art.o 65. da Constituição da República Portuguesa, e ainda assegurar a receção do conceito de ambiente urbano inscrito na alínea e) do n.o 2 do art.ㅇ 66. da Constituição da República Portuguesa."
}

Uma dúvida que se coloca é a de sabermos qual a percentagem das mais-valias que será afeta à tal dimensão social? Serão cinquenta por cento, como defendem alguns autores (Carvalho e Oliveira, 2013), ou a totalidade como defende o CNADS (CNADS, 2013) ${ }^{21}$ ? A lei não esclarece este aspeto fundamental. Como resulta da experiência internacional, com melhores resultados do ponto de vista do controlo do desenvolvimento urbano e da justiça social e espacial, a Lei deveria consagrar o princípio de que as mais-valias geradas pelos atos da Administração Pública devem ser por ela recuperadas (Booth (2012); Correia (1993); Fainstein (2012); Muñoz (2008); Needham (2003); Needham (2004); Needham (1992); Renard (2001); Renard (1998).

Needham (2003) propõe-nos uma interpretação que tem implícita uma leitura sobre a dimensão económica do desenvolvimento urbano. Ele gera uma mais-valia. Mais-valia que Needham $(2003$, p10) identifica como "a gift of the planner" 22 e que considera ser difícil "to justify politically that the landowner retains it." 23 O que está aqui em causa é o facto de ser a Administração, através do planeamento urbanístico (...) quem gera as mais-valias e de

$20 \quad$ Parecer da OA In https://www.parlamento.pt/ActividadeParlamentar/Paginas/Detalhelniciativa.aspx?BID=38024

21 Parecer do Conselho Nacional do Ambiente e do Desenvolvimento Sustentável (CNADS), sobre a Proposta de Lei N.o 183/XII - Proposta de Lei de Bases da Política Pública de Solos, de Ordenamento do Território e de Urbanismo inhttps://www.cnads.pt/index.php?option=com docman\&task=cat view\&gid=62\&ltemid=84

22 "Uma prenda do planeador". TdP.

23 "justificar politicamente que o proprietário do solo a retenha". TdP. 
serem os proprietários dos terrenos objeto desse planeamento a capturá-las. Não se trata apenas de perceber o mecanismo da sua geração mas também de perceber quem, como e quando, captura essas mais-valias. Há uma evidência de que as mais-valias simples são geradas por decisões da Administração. Correia (2003), refletindo sobre a situação em Portugal reconheceu que a Administração Pública por via dos planos que aprova determina mais-valias que o mercado reconhece mas não as consegue recuperar. Uma questão importante que Needham (2003) também aborda é a de saber quem tem o direito a esta mais-valia. Fá-lo numa perspetiva em que a dimensão de justiça social associada ao desenvolvimento urbano não pode ser ignorada.

\begin{abstract}
"The answer to this question also has aspects of equity and social justice. Is it considered right that someone who has the good fortune to own land in a particular location becomes rich, because a public authority changes the zoning from agriculture to housing in that location, or because a road authority builds a motorway with a junction near to that location? Is it considered right that rules for redistributing a financial surplus on a development project should work out differently in commercially booming areas than in depressed areas? We must look for a social or political answer rather than a legal one." (Ibidem,p.9) ${ }^{24}$
\end{abstract}

Se atendermos ao que referimos sobre a produção da lei, na Nota Técnica no 3 esclarecia-se que a opção pela socialização da mais-valia não tinha uma base tributária, apontando-se para a criação de uma Bolsa de Terrenos a integrar no Património Público Municipal, como compensação pela mais-valia apropriada pelo proprietário/promotor. Esta situação não está clarificada na lei aprovada. Os Planos devem aplicar os mecanismos perequativos para que os proprietários de uma determinada área objeto de um Plano Territorial sejam tratados em pé de igualdade, quer quanto aos benefícios - área de construção proporcional à área de terreno de que são proprietários - quer quanto aos encargos - participação nos custos de infraestruturação e de construção dos equipamento coletivos da área objeto do Plano - e devem, ao mesmo tempo, determinar a afetação pública das mais-valias.

\footnotetext{
24 “A resposta a esta questão envolve aspetos de equidade e justiça social. É considerado justo que alguém que teve a boa fortuna de possuir terra numa localização particular se torne rico, porque uma autoridade pública altera o uso do solo de solo agrícola para solo urbanizável numa determinada localização, ou porque uma autoridade rodoviária constrói uma auto-estrada com uma ligação próxima dessa localização? É considerado justo que as regras para redistribuir a mais valia de um projeto urbano seja diferente em áreas em expansão ou em áreas deprimidas? Devemos procurar uma resposta social e política mais do que uma resposta legal."
} 


\section{Proposta de afetação social da mais-valia}

A lei consagra a afetação social das mais-valias mas não define regras para a sua parametrização e não estabelece a percentagem da mais-valia a socializar. Talvez por isso nada diga sobre a forma e o tempo de efetuar o seu pagamento. Apesar da evolução verificada com a nova Lei domina ainda o conservadorismo fiscal que nos tem caracterizado quando se trata da relação com a propriedade imobiliária e, em particular, quando se trata de taxar a produção de solo urbano. Propomos, para romper com este paradigma, a socialização da totalidade da mais-valia gerada.

Importa clarificar aquilo que se entende por mais-valia. Estamos a falar da mais-valia que corresponde ao acréscimo de valor de um prédio em resultado da autorização de uma alteração de uso a nível administrativo para esse mesmo prédio. São independentes de qualquer intervenção ou mérito do proprietário. Resultam sobretudo da mudança de uso do solo rústico para urbano em resultado de uma alteração dos planos de uso do solo. É o que acontece quando uma autarquia toma a decisão de incluir dentro do perímetro urbano um determinado conjunto de solos rústicos Neste caso, a mais-valia resulta da diferença de valor entre o solo rústico e o urbano e é proporcional ao índice de utilização permitido em função da distribuição da área pelos diversos tipos de utilização. As mais-valias simples podem, ainda, ser determinadas pela mudança de utilização de espaços edificados e pela densificação ou requalificação urbanas (Muñoz, 2008), sobretudo associada à reabilitação dos centros históricos.

A socialização que propomos é feita com base num diferencial do valor entre o solo rústico e o solo urbano oficialmente estabelecido e válido a nível nacional. Na investigação realizada propusemos para Alcochete o valor de 300 euros $/ \mathrm{m}^{25}$. Os construtores de edifícios conhecem em cada momento o Valor de Venda (VF) dos seus projetos, em função das tipologias, das áreas, maiores ou menores, da localização e do funcionamento do sistema financeiro, em particular do nível de empréstimo que os eventuais compradores podem obter para adquirirem uma determinada tipologia. Em função desse conhecimento, somado ao conhecimento dos Custos da Operação, e aos Lucros que pretende obter, para

\footnotetext{
${ }^{25} \mathrm{O}$ valor de 300,00 euros/m2 está fundamentado numa investigação anterior, no âmbito da Tese de Doutoramento que o autor desenvolveu.
} 
remunerar o investimento feito, fazem aquilo a que os franceses chamam "Le Compte à Rebours" (Martin, 1993), literalmente o cálculo às avessas, para determinar o máximo valor a pagar pelo terreno no qual irão construir. Considerando um valor de venda de 200 mil euros, para uma tipologia T3 com uma área de $140 \mathrm{~m} 2$, constatamos que o valor a pagar pelo terreno pronto a construir será próximo dos 50 mil euros. Neste caso o valor a pagar pelo terreno será de $355 € / \mathrm{m} 2$. Se descontarmos o custo de urbanização que é da ordem dos $50 € / \mathrm{m} 2$ obtemos e $305,00 € / \mathrm{m} 2$ para o preço a pagar pelo solo.

Admitindo que o solo rústico tinha um valor da ordem dos $5,00 € / \mathrm{m} 2$ a mais-valia capturada pelo proprietário seria de 300,00 €/m2. Como o solo urbanizado excede em muito a área de implantação das edificações a quantificação da mais-valia é afetada pelo índice de utilização do solo definido no IGT aplicável. Digamos que se o iu for de 0,5 a mais-valia para a totalidade do solo será de $150 € / \mathrm{m} 2$. Podem existir outros valores relativamente próximos deste mas com diferenças justificadas para um determinado contexto. Enquanto não existir uma tabela de preços oficialmente fixada há apenas uma verdade que ninguém parece poder questionar: o processo de desenvolvimento urbano gera uma mais-valia simples.

No caso da reabilitação urbana, sempre que exista uma mudança de uso dentro do uso urbano, por exemplo habitação para serviços ou para habitação de luxo, ou habitação permanente para alojamento local, toda a área abrangida deve ser objecto da cobrança do mesmo valor de mais-valia. $O$ art. $66^{26}$ da Lei deve passar a ter uma redação que clarifique aquilo que se entende por afetação social da mais-valia. Para isso é necessário rever o arto 66ำ e introduzir um novo artigo que indique de forma clara quais são as políticas públicas que beneficiarão da afetação social das mais-valias mas que, além disso, estabeleça a percentagem da mais-valia global que é afeta a cada um delas.

$\mathrm{Na}$ nossa proposta ${ }^{27}$, a mais-valia gerada destina-se a financiar as seguintes políticas públicas: habitação; educação; saúde; solidariedade social; solidariedade regional; política salvaguarda do património monumental. Quarenta por cento da mais-valia será afetada à Política de Habitação, vinte por cento às Políticas Públicas de Educação e Saúde e os

\footnotetext{
${ }^{26}$ Esta proposta e as restantes apresentadas neste artigo destinam-se apenas a mostrar uma possibilidade concreta de alterar a Lei de acordo com a proposta de mudança da política. Não se trata de uma proposta revista na perspetiva do Direito e da normal produção legislativa, nem pretende situar-se nesse nível.

${ }^{27}$ No Anexo I apresentamos uma proposta de redação que responde a todas as questões que consideramos importantes clarificar. Naturalmente, não existe a intenção de obter uma redação juridicamente estabelecida, já que a nossa formação não o permite.
} 
restantes 40 por cento às Políticas Públicas de Solidariedade Regional, Solidariedade Social e à Recuperação do Património Monumental. Importa destacar que vinte por cento da maisvalia gerada no país num determinado período seria destinada à solidariedade regional. Além dessa verba fixa há ainda outros vinte por cento canalizados para as políticas públicas de solidariedade social e de reabilitação do património monumental cujo impacto nos territórios de baixa densidade tenderá a ser elevada. Trata-se de reconhecer que o país é desigual, que existem acentuadas assimetrias entre litoral e interior e que nos ciclos de desenvolvimento vividos, com ênfase no último impulsionado pelo investimento no imobiliário, essa desigualdade se reforçou. A necessidade que Portugal sentiu de implementar um programa nacional para a coesão territorial é disso o mais expressivo testemunho. A proposta de afetação social das mais-valias pretende contribuir para concretizar os objetivos da equidade territorial e de promoção de um desenvolvimento mais justo, não apenas do ponto de vista urbano, mas também na articulação entre o meio urbano e os meios rurais, ou, de forma mais geral, na articulação entre o litoral e o interior, como se defende, aliás, no Programa Nacional para a Coesão Territorial $(P N C T)^{28}$. Se equacionarmos a socialização das mais-valias, sem determinar previamente a sua afetação social, o desenvolvimento desigual acentuar-se-á, com as regiões litorais e as áreas metropolitanas a beneficiarem dessa mudança e o interior a não o poder fazer.

Discutida a questão crítica da afetação social das mais-valias uma outra questão pertinente é saber como se pode efetuar o pagamento e quando deve ele ser concretizado. 0 pagamento deve ser concretizado na mesma altura em que a mais-valia é gerada. Importa por isso referir o seguinte: no ciclo do imobiliário existem três fases distintas que são o planeamento do uso do solo, a urbanização e o licenciamento e edificação. As mais-valias geram-se na primeira fase, a do planeamento. Acontece que essa geração ocorre - no quadro atual vigente em Portugal - no momento em que é aprovado o Plano Diretor Municipal ${ }^{29}$. Essa aprovação não determina que todo o território abrangido vai passar para a fase de urbanização. Por essa razão a aprovação do PDM apenas nos indica as mais-valias

\footnotetext{
${ }^{28}$ O Programa Nacional para a Coesão Territorial foi aprovado pela resolução do Conselho de Ministros $\mathrm{n}$ o 72/2016, publicada no Diário da República n.ㅇ 226/2016, Série I de 24.11.2016. http://www.portugal.gov.pt/pt/o-governo/pnct/pnct.aspx

${ }^{29}$ Pode-se argumentar que este modelo é um modelo do passado, muito baseado na expansão urbana. É verdade, mas trata-se do modelo vigente em Portugal ao longo de décadas, que permite analisar e compreender o processo de geração das mais-valias urbanísticas. Nos casos de requalificação urbanística mantêm-se válido o princípio de que as mais-valias geram-se na fase do planeamento.
} 
potenciais que o Plano configura. Nas últimas décadas, como resulta da investigação realizada em Alcochete, são os promotores que determinam o início do processo de urbanização. Neste contexto a cobrança da mais-valia deve ser feita no momento em que o projeto é aprovado. Idealmente o processo de urbanização apenas se deve iniciar depois de a autarquia elaborar o planeamento de pormenor para a parte do território que entendeu, no âmbito da sua programação, dever ser aquele cujo processo de urbanização/edificação avançará de imediato. Após a aprovação do planeamento de pormenor ${ }^{30}$ a mais-valia é devida e deve ser paga por cada um dos beneficiados com o desenvolvimento. O pagamento deve ser feito em dinheiro e em terrenos, com efetivo potencial edificatório e/ou importância urbanística, não podendo o valor destes ultrapassar os 20 por cento da maisvalia a pagar. Isto resulta do facto de existirem transferências obrigatórias para a solidariedade regional que não podem ser feitas em terrenos, e havendo parte das verbas que não serão geridas pelas autarquias. Propomos um novo artigo no Regime Jurídico da Urbanização e Edificação que trate desta questão, como explicamos a seguir.

\subsection{Taxas municipais de urbanização e outros impostos}

Como resultado da socialização das mais-valias é imperativo que, por razões de justiça social e de simplificação administrativa, se acabe com a cobrança pelos municípios de taxas que oneram os proprietários e promotores de novas urbanizações ${ }^{31}$ e de novos espaços edificados. Por isso entendemos que deve ser contemplado no Regime Jurídico da Urbanização e Edificação - Decreto-lei 136/2014 de 9 de Setembro - a eliminação do Capítulo V - Taxas inerentes às operações urbanísticas, bem como dos artos 1160 e 117으 na sua atual formulação. Deve ser criado um novo Capítulo $V$, cuja designação será "Pagamento da Mais-Valia Urbanística". O art. 116 deverá ter uma redação clara sobre o momento em que a mais-valia é devida, o momento em que ela deve ser paga, as condições

\footnotetext{
${ }^{30} \mathrm{Na}$ generalidade das situações, ao longo das últimas décadas, o planeamento de pormenor quase não esteve presente no ciclo do imobiliário. A investigação realizada em Alcochete mostrou que, no entanto, a existência deste tipo de IGT não impediu nenhuma das patologias que caracterizaram o desenvolvimento urbano das últimas décadas.

${ }^{31} \mathrm{O}$ conceito de promotor de urbanizações deixa de fazer sentido caso se proceda à devolução ao Estado do direito de urbanizar. Esta hipótese, e as suas consequências, foi analisada no âmbito da nossa investigação, embora não seja aqui abordada.
} 
de faseamento desse pagamento e as formas de que se poderá revestir o pagamento, em dinheiro ou em género ${ }^{32}$.

\section{Política pública de habitação}

O Governo aprovou, em Outubro de 2017, uma Resolução do Conselho de Ministros que estabelece o sentido estratégico, objetivos e instrumentos de atuação, para uma "Nova Geração de Políticas de Habitação" (NGPH). Foi colocado à discussão pública o documento que estrutura essa proposta de política pública tendo o IHRU divulgado, em Fevereiro de 2018, o Levantamento Nacional das Necessidades de Realojamento Habitacional. Os grandes objetivos que esta NGPH pretende concretizar são os seguintes: dar resposta às famílias que vivem em situação de grave carência habitacional; garantir acesso à habitação aos que não têm resposta por via do mercado; criar as condições para que a reabilitação seja a principal forma de intervenção ao nível do edificado e do desenvolvimento urbano; promover a inclusão social e territorial e as oportunidades de escolha habitacionais. Se compararmos estes objetivos com os definidos no Programa Nacional da Política de Ordenamento do Território (PNPOT), ${ }^{33}$ verificamos que no essencial a situação não se alterou. Esse importante documento de política pública tinha vindo reconhecer as insuficiências do nosso modelo de desenvolvimento urbano e apontar alguns caminhos para corrigir as situações detetadas. Por exemplo, no 4ำ Objetivo Estratégico (Capítulo 2 do Programa de Ação do PNPOT, p39) pretendia-se assegurar a equidade territorial no provimento de infraestruturas e de equipamentos coletivos e a universalidade no acesso aos serviços de interesse geral, promovendo a coesão social" e, entre outros Objetivos Específicos, "melhorar as condições de habitabilidade nomeadamente no que se refere aos grupos sociais mais vulneráveis". Na mesma altura em que foi aprovado o PNPOT, Ghekiére (2007) fazia uma análise sobre a Política de Habitação Europeia com a atenção centrada na habitação social. Analisando a diversidade de conceções europeias no que se refere à

\footnotetext{
${ }^{32}$ No Anexo I, apresentamos uma proposta de redação que responde a todas as questões que consideramos importantes clarificar. Naturalmente, não existe a intenção de obter uma redação juridicamente estabelecida, já que a nossa formação não o permite.

${ }^{33}$ O PNPOT foi aprovado pela lei no 58/2007 de 4 de Setembro.
} 
habitação social, Ghekiére incluiu Portugal num conjunto de países com uma conceção residual da habitação social integrando os países que mais se afastam do ideal do modelo social europeu. No âmbito do Plano Estratégico de Habitação para o período de 2008 a 2012, Guerra (2008) caracterizava as dinâmicas e políticas habitacionais europeias no princípio do milénio, tendo como pano de fundo a generalização de um modelo de produção liderado pelo mercado. Guerra (2008. p.47-48) identificava algumas ideias fortes que dominavam o debate europeu sobre as questões da habitação, com destaque para as seguintes:

\footnotetext{
“2 - A crença de grande parte dos analistas ocidentais de que a maioria dos problemas habitacionais estão resolvidos pelo menos naquilo que tradicionalmente se apelida de carências quantitativas;

3 - O predomínio da defesa da retirada do Estado da produção direta de habitação, o seu enquadramento num olhar mais estratégico sobre a política das cidades acompanhado de uma profunda crítica à geração de políticas anteriores."
}

Este predomínio de um conjunto de teses que valorizam o papel do mercado e o seu desempenho, eram o reflexo de uma hegemonia de especialistas académicos e empresariais ligados ao mercado, como a autora então reconhecia. A crise de 2008 veio questionar de forma contundente essas crenças e confirmar aquilo que uma análise mais atenta da realidade mostrava: os "novos problemas da habitação" eram afinal a reprodução dos "velhos problemas da habitação", resultantes da incapacidade do Estado em garantir o respeito pelo desígnio constitucional do direito à habitação. Voltando à "Nova Geração de Políticas de Habitação" constatamos que a ambição, no que se refere à habitação social, é passar de $2 \%$ do parque habitacional para $5 \%$ do parque no médio prazo, quer dizer no prazo de 8 anos. Isso representa um acréscimo de 170 mil fogos com apoio público até 2026, admitindo que a aplicação da nova política se inicia em 2019. Os vários instrumentos previstos para concretizar os objetivos da nova política passam muito pelos incentivos fiscais para as entidades públicas e privadas, coletivas e singulares, pelas isenções de tributação de parte significativa do IMI - até $50 \%$ - pela fixação de um valor de renda inferior em $20 \%$ ao valor de mercado ou pela fixação de limites à taxa de esforço, compatibilizando o valor da renda com o rendimento dos arrendatários entre outros. Apela igualmente a políticas municipais que passam entre outras medidas pela "redução significativa ou eliminação da componente de custo do terreno/edifício". Não pretendemos fazer uma análise detalhada da Nova Geração de Políticas de Habitação, até porque o processo não está ainda concluído. Queremos apenas colocar mais uma vez em evidência o 
facto de se ter tornado comum a criação de novas estratégias, de novas visões para o desenvolvimento estratégico, de novos instrumentos, de uma qualquer política pública, sem fazermos previamente uma pergunta fundamental: quais são os recursos que nos irão permitir financiar as novas políticas que desenhámos? Neste caso opera-se ainda num quadro anterior à alteração da Lei de Solos e ignora-se a possibilidade que a Lei consagra de procedermos à socialização das mais-valias. As propostas de intervenção existentes caracterizam-se, hoje como no passado, pela fraca dotação de verbas - dos programas "Da Habitação ao Habitat" e "Porta ao Lado" - não se percebendo como se fará a sua distribuição pela totalidade do território nacional, caso o programa não tenha apenas uma escala metropolitana. A agudização dos problemas relacionados com o acesso à habitação aconteceu com a crise da economia global e do sistema financeiro e intensificou-se, curiosamente, com a saída da crise, muito impulsionada pelo turismo e pelas dinâmicas a ele associadas, em países como Portugal, sujeitos durante alguns anos à intervenção externa. Quer numa situação de grave recessão, quer num período subsequente de crescimento económico, as políticas de habitação são vítimas da mesma falta de recursos. Para mostrar como no quadro legal existente, feita a clarificação do que se entende por afetação social das mais-valias, é possível encontrar os recursos necessários para financiar a política de habitação, apresentamos um caso prático resultado da investigação que conduzimos em Alcochete.

\subsection{Afectação social das mais-valias à política de habitação. Um caso práctico.}

Voltando ao exemplo empírico desta investigação, Alcochete integra a Área Metropolitana de Lisboa, situando-se na sua parte Sul e fazendo parte do distrito de Setúbal. Tem uma extensa frente ribeirinha a confrontar com o rio Tejo tendo uma parte significativa do seu território integrado na Reserva Natural do Estuário do Tejo. No final do século passado houve a construção de grandes infraestruturas que reforçaram a ligação entre as margens norte e sul da $A M L$ e que determinaram uma alteração do padrão de ocupação dos respetivos territórios. O desenvolvimento de Alcochete foi muito influenciado pela construção da Ponte Vasco da Gama, que determinou um aumento de procura de terrenos no concelho de Alcochete e no concelho vizinho do Montijo. A população de Alcochete aumentou 72,7\% entre 1991 (10.169hab) e 2011 (17.569 hab). Como foi referido no 
PEDESPES este crescimento teve como suporte uma importante expansão das áreas urbanas. Alcochete no conjunto das suas áreas urbanas totalizava 136,99 hectares. Com a expansão dos perímetros urbanos aumentaram 372,29 hectares as áreas urbanizáveis, suficientes para alojar 29.228 habitantes. ${ }^{34}$ As coisas não se passaram assim porque a crise de 2008 veio travar a expansão urbana. Na figura seguinte mostramos as mais-valias geradas, entre 1997 e 2015, pela aprovação dos IGT no concelho de Alcochete. Distinguimos entre as mais-valias geradas e as mais-valias capturadas, já que dos 372,29 hectares de Espaços Urbanizáveis de Expansão, apenas 130,07 foram urbanizados. Importa referir que a mudança de uso do solo na origem das mais-valias, concretizou-se na sua maioria à custa de solos integrantes das Reservas Ecológica e Agrícola. Essa mudança de uso concretizou-se da seguinte forma: desafetação de prédios que integravam a Reserva Ecológica Nacional, num total de 295,17 hectares e desafetação de prédios que integravam a Reserva Agrícola Nacional, num total de 30,74 hectares.

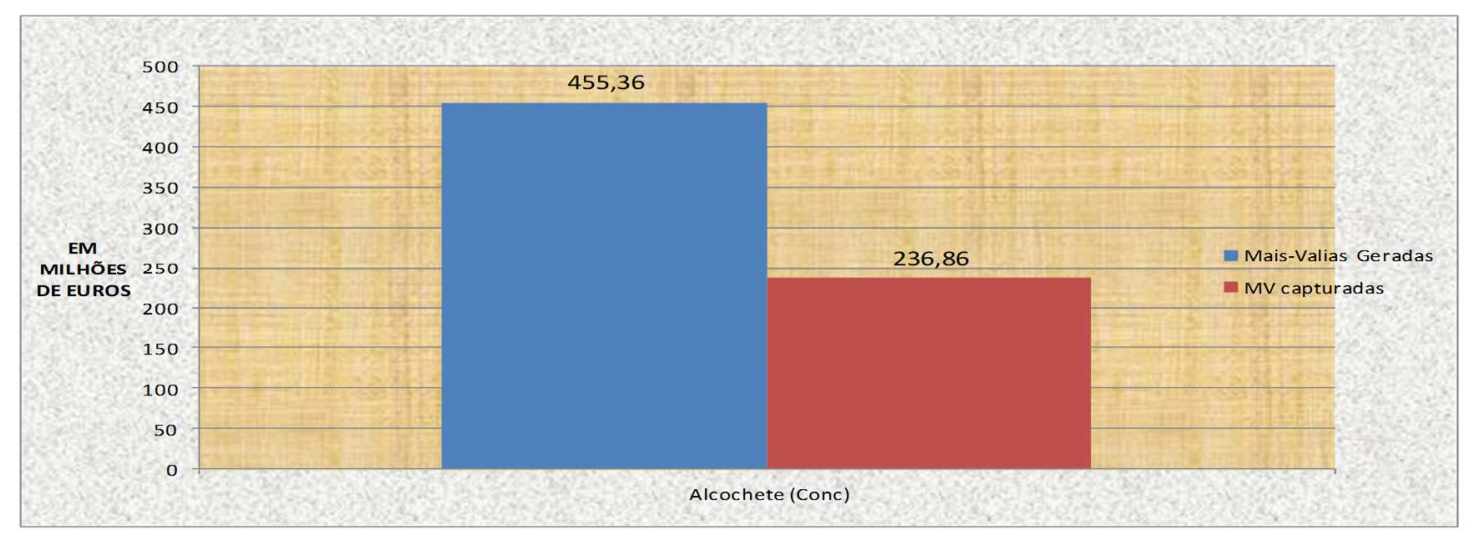

Figura 1 - Síntese da Evolução das Mais Valias em Alcochete

Fonte: PDM Alcochete. Elaborado pelo próprio

No mesmo período as receitas totais obtidas pelo município foram de apenas 9 milhões de euros. Logo que as receitas com o imobiliário estagnaram os Resultados Líquidos dos sucessivos exercícios foram afetados. Na Figura 2 mostramos a evolução das receitas do concelho de Alcochete e dos resultados líquidos obtidos pela autarquia entre 2000 e 2015.

\footnotetext{
${ }^{34}$ Ver PEDESPES - Plano Estratégico para o Desenvolvimento da Península de Setúbal. Diagnóstico Prospectivo - Questões Urbanas - p.21 e 24
} 


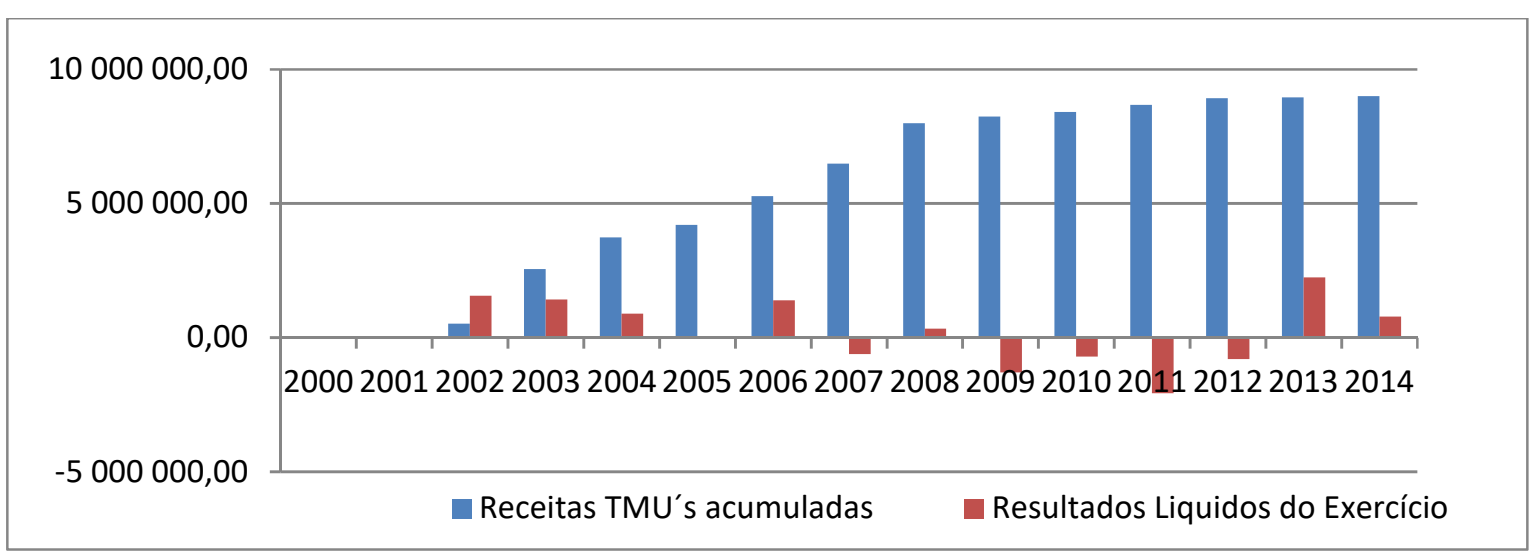

Figura 2 - Evolução da receita. Taxas Municipais de Urbanização versus Resultados Líquidos do Exercício

Fonte: Contas de Gerência CM Alcochete. Elaborado pelo próprio

Analisando as Grandes Opções do Plano do município entre 2009 e 2015 verificamos que entre as medidas relacionadas com a Habitação aparece sempre um conjunto relevante de objetivos. "Desenvolver Políticas de Solos que estimulem o Mercado Habitacional a Custos Controlados e o Arrendamento Social" é a medida que consta em todos esses documentos oficiais da autarquia de Alcochete. No entanto a análise quer dos Orçamentos previsionais quer das Contas de Gerência dos exercícios entre 2009 e 2014 permite-nos chegar às seguintes conclusões: no ano de 2009 a despesa com habitação prevista foi de 100,00 euros; No ano de 2010 essa despesa subiu para 1000,00 euros; Em 2011 situou-se em 180,00 euros e nos três anos seguintes foram sempre orçamentados 200,00 euros. $\mathrm{Na}$ verdade em todos esses anos o Município de Alcochete, de acordo com as Contas de Gerências aprovadas pela A. Municipal, não realizou qualquer despesa relacionada com Habitação. Tendo em conta a nossa proposta para a afetação social das mais-valias, neste caso a parte mobilizada para a política de habitação, e recorrendo aos resultados obtidos ao longo da investigação efetuada em Alcochete, obtemos os resultados mostrados na figura seguinte. 


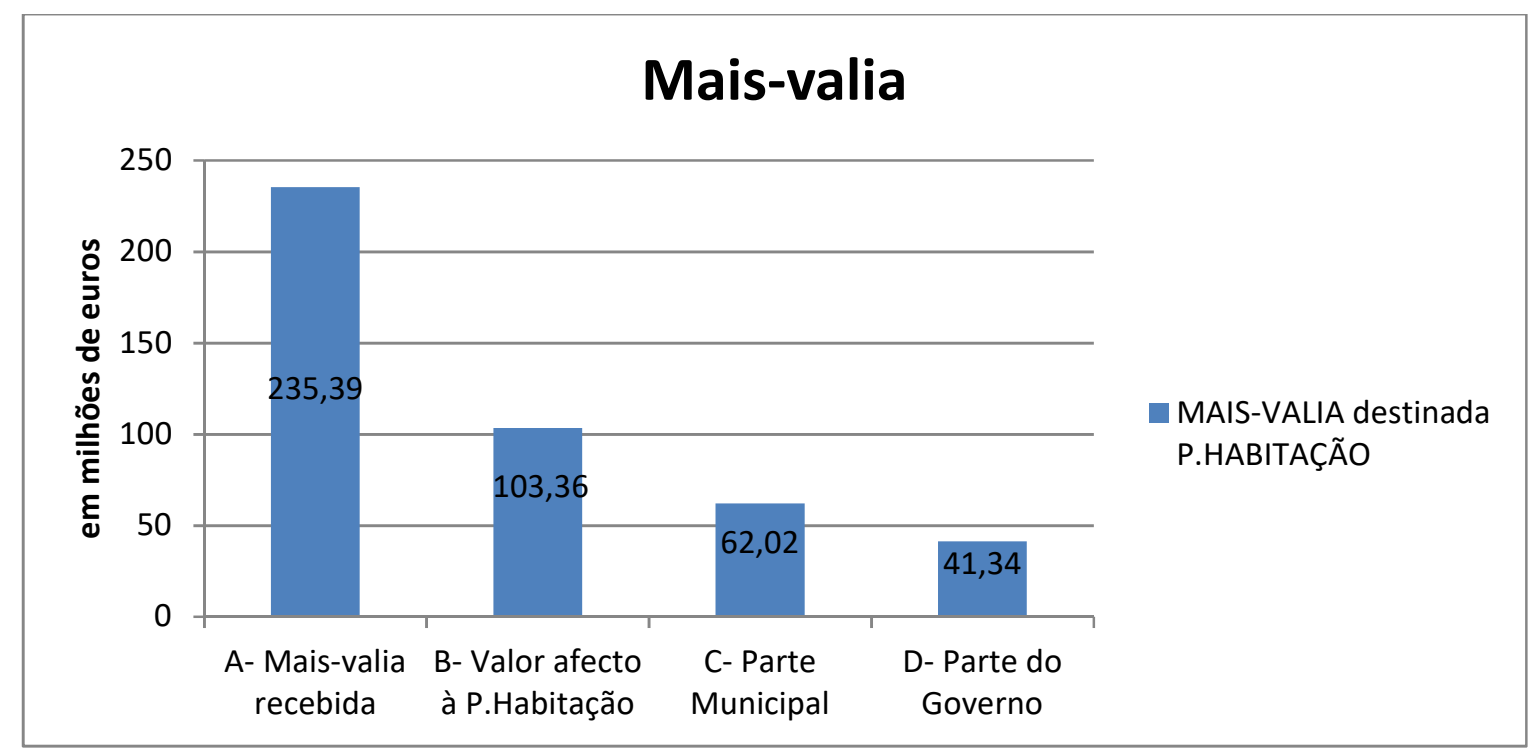

Figura 3- Proposta de Afetação das Mais-Valias aplicada ao financiamento da Política de Habitação.

O que o gráfico nos mostra é que o município de Alcochete teria podido utilizar ao longo dos últimos quinze anos um valor médio anual de 3,76 milhões de euros para financiar a sua política de habitação.

\section{Conclusões}

A proposta que aqui apresentamos é concretizável no atual quadro legal. Basta clarificar um aspeto que a Lei no 31/2014 não cuidou de esclarecer: a afetação social das mais-valias. Os recursos existem e a sua afetação social está prevista na Lei. Falta apenas quantificar o valor da mais-valia e determinar as formas da sua afetação social. A nossa proposta resulta da investigação conduzida em Alcochete e da reflexão sobre a forma como o desenvolvimento urbano evoluiu e sobre as suas consequências. Esta proposta permitiria ao Estado ter uma Politica de Habitação articulada com o Programa Nacional da Politica de Ordenamento do Território. E permitiria a cada município ter uma Politica de Habitação, consagrada no seu Plano Local de Habitação, articulada com a Politica de Habitação Nacional. Um quadro legal com estas características possibilita uma abordagem completamente diferente, do papel e da intervenção do Estado na sua função reguladora da intervenção no território e na promoção da justiça social e espacial. 
Além da produção de habitação para os diferentes grupos sociais - de que o sector privado, enquanto produtor, beneficiaria bastante - colocam-se outras possibilidades: flexibilização da mudança de habitação ao longo do ciclo de vida; facilitar a mobilidade do fator trabalho reduzindo o espartilho imposto pela posse da habitação e pelo endividamento associado; equilíbrio nas formas de acesso entre aquisição e arrendamento; equilíbrio tendencial entre parque público e parque privado para o mesmo fim; manutenção regular do parque público de habitação; tendência para uma estabilização do parque público a médio prazo. Falamos de uma outra resposta, construída a partir dos mesmos dados. Uma resposta em que os valores da equidade e da inclusão, da solidariedade regional e do ordenamento do território, passam a dispor de todas as condições para serem realidades percebidas pelas populações. Passaríamos a ter um Estado regulador capaz de contribuir para financiar a intervenção do Estado produtor em complementaridade com a intervenção do Mercado, sem a distorção imposta pelo domínio das suas componentes especulativas.

\section{Referências bibliográficas}

ALTERMAN, Rachelle. Land-Use Regulations and Property Values. The "Windfalls Capture" Idea Revisited. In "The Oxford Handbook of Urban Economics and Planning". Nova lorque: Editado por Nancy Brooks, Kieran Donaghy and Gerrit-Jan Knaap. 2012. pp.755-786

BOOTH, Philip. The Unearned Increment : Property and the Captur of Betterment Value in Britain and France. In Value Capture and Land Policy, Land Policy Conference. Cambridge: Ingram, Gregory. K. and Hong Yu-Hung . Lincoln Institute of Land Policy.2012. 74-94. ISBN 978-1-55844-227-6

BUSQUETS, Joan. La construcción urbanística de una ciudad compacta. Barcelona: Ediciones del Serbal.2004. ISBN 84-7628-458-6

CAETANO, Mário; CARRÃO, Hugo; PAINHO, Marco. Alterações da ocupação do solo em Portugal entre 19852000. Instituto do Ambiente. 2005.

CARVALHO, Jorge; OLIVEIRA, Fernanda Paula. Parecer sobre a Proposta de Lei no 183/XII - Proposta de Lei de Bases da Política de Solos, de Ordenamento do Território e de Urbanismo. 2013.

CHALINE, Claude(). Les Politiques de la Ville. Paris : Presse Universitaire de France. 2006/1997.

CORREIA, Paulo V.D. Políticas de Solos No Planeamento Municipal. Fundação Calouste Gulbenkian. Lisboa. 1993. ISBN 972-31-0599-3

CORREIA, Paulo V.D. Vantagens e Inconvenientes da Codificação Global da Legislação do Urbanismo. In 2을 Colóquio Internacional: um Código de Urbanismo para Portugal. Coimbra: CEDOUA, APDU.2003.

deWOLFF, Herman. The new Dutch Land development Act as a tool for value capturing. International Conference "Sustainable Areas". $\quad$ Rotterdam. 2007. https://www.yumpu.com/en/document/view/28100591/the-new-dutch-land-development-act-as-a-tool-forvalue-capturing. 
FAINSTEIN, Susan. The Just City. Ithaca and London: Cornell University Press. 2010. ISBN 0801476909

FAINSTEIN, Susan. Land Value Capture and Justice. In Value Capture and Land Policy, Land Policy Conference. Cambridge: Ingram, Gregory. K. and Hong Yu-Hung . Lincoln Institute of Land Policy.2012. 14-24. ISBN 978-155844-227-6

GHEKIÉRE, Laurent. Le Logement social dans les 27 États membres. Du résiduel à l'universel. In Habitat et Societé, no 46, Junho 2007. pp.30-34.

GUERRA, Isabel. Europa e Políticas Habitacionais. Mudanças em Curso.In Revista Cidades, Comunidades e Territórios. Lisboa: ISCTE, 2008.

HARVEY, David. A Brief History of Neoliberalism. Oxford : Oxford University Press. 2005. ISBN 9780-19928327-9

HARVEY, David. Rebel.Cities. From the right to the City to the Urban Revolution. Londres. Verso .2012. ISBN 978$1-84467-882-2$

HARVEY, David. The Right to the City. New Left Review. 2008. in http://urbanuprising.org/sites/default/files/files/righttothecity.pdf

Harvey, David. Possible Urban Worlds. Megacities Lecture2000. Amersfoort : Twynstra Gudde. 2000.

MARTIN, Jean-YvesCompte à Rebours du Promoteur et Raisonnement de l' aménageur. In Granelle, JeanJacques, \&Vilmi, Thierry. L' articulation du foncier et de l' imobilier. Paris : ADEF. 1993. pp. 77-88.

MUÑOZ GIELEN, Demétrio Public Value and the financing of public infraesctruture in England, Valência and the Netherlands. Comunicação ao International Academic Forum, Planning, Law and Property Rights .AESOP. Warsaw. 2008.http://www.urbsadvies.nl/attachments/Paper_Demetrio_Muoz submitted version.pdf.

HARTMANN, Thomas; NEEDHAM, Barrie. Planning, by Law and Property Rights Reconsidered. London: Ashgate.2012. ISBN 978-1-4094-3721-5

NEEDHAM, Barrie. Planning, Law and Economics: The rules we make for using land. Londres: Routledge. 2006. ISBN 978-0-415-34374-9

NEEDHAM, Barrie. The new Dutch spatial planning act. Continuity and change in the way in wich the Dutch regulate the practice of spatial planning. GAP - Research Group Governance and Places- University of Nojmegen. Working Paper Series. 2004.

NEEDhAM,Barrie, Verhage, RoelofThe Politics of Land Policy: Using Development Gains for Public Purposes. In http://www.iul-urbanisme.fr.2003.

NEEDHAM, Barrie. A Theory of Land Prices When Land is Supplies Publicly. The case of Netherlands. Urban Studies. 1992. Vol. 29, n.o 5. pp. $669-686$.

NOZICK, Robert. Anarchy, State, and Utopia. Nova lorque: Basic Books, 1974. ISBN 978-0-465-05100-7

RENARD, Vincent. L'économie du logement: le préalable foncier. in SEGAUD Marion, BONVALET, Catherine, BRUN, Jacques . Logement et Habitat - L'état des savoirs. Paris :. 1998, pp. 201-209

SOJA, Edward. Seeking Spatial Justice. London: University of Minnesota Press. 2010. ISBN 978-0-8166-6668-3 


\title{
ANEXO I
}

\author{
LEI № 31/2014
}

de 31 de maio

LEI DE BASES GERAIS DA POLÍTICA PÚBLICA DE SOLOS, DE
ORDENAMENTO DO TERRITÓRIO E DE URBANISMO.

TÍTULO V

Regime económico e financeiro

CAPÍTULO II

Instrumentos equitativos

\section{Artigo 66.}

Tipos de redistribuição de benefícios e encargos

Constituem tipos de redistribuição de benefícios e encargos:

a) s/alteração;

b) s/ alteração;

c) s/alteração;

d) Passa a ser fixado um diferencial oficial entre o valor do solo rústico e do solo urbano, válido para todo o território nacional. Este valor é revisto de três em três anos e publicado na mesma altura em que é aprovado o OE para o ano seguinte.

e) Fica oficialmente fixado, para o primeiro triénio, o valor de $300 € / \mathrm{m} 2$ para ser aplicado no cálculo das mais-valias em todos os IGT. Este valor é corrigido pelos índices de utilização fixados em cada plano.

Deve passar a existir um artigo da Lei que defina o que se entende por "afetação social da mais-valia". Propomos um art. 66-A com a seguinte redação:

\section{Artigo 66.-.A}

\section{Definição da Afectação Social da Mais-Valia}

1 - A afetação social da mais-valia significa que as receitas associadas à sua socialização são destinadas a financiar as seguintes políticas públicas:

a) politica pública de habitação;

b) politica pública de educação;

c) politica pública de saúde;

d) politica pública de solidariedade social;

e) politica pública de solidariedade regional;

f) politica pública de reabilitação do património monumental 
2 - As mais-valias cobradas em cada município têm a seguinte afetação por cada uma das políticas públicas:

a) A parte destinada a financiar a política pública de habitação representa $40 \%$ da mais-valia recebida;

b) A parte destinada a financiar as políticas públicas de solidariedade social, regional e a reabilitação do património monumental, representam $40 \%$ da totalidade da mais-valia recebida. A parte destinada à solidariedade regional não pode ser inferior a $50 \%$ deste valor.

c) A parte destinada a financiar a politica pública de educação e saúde é, para cada uma destas politicas, $10 \%$ da mais-valia total recebida.

3 - A parte da mais-valia destinada a financiar as políticas públicas estabelecidas no ponto 1 nas alíneas d), e) e f), é gerida pelas autoridades regionais e, no caso de estas não existirem, pelo ministério que as tutela.

4 - A parte destinada a financiar a política pública de habitação é gerida de acordo com a seguinte distribuição pelos municípios e pelo Governo. Sessenta por cento da mais-valia é gerida pelo município e os restantes quarenta por cento são afetos à política nacional e regional neste domínio.

5 - A parte da mais-valia destinada a financiar as políticas públicas de educação e de saúde, são geridas de acordo com a seguinte distribuição pelos municípios e pelo Governo: Setenta por cento da receita é gerida pelo município e o restante pelo Governo.

Republicação do Decreto -Lei n.o 555/99, de 16 de dezembro

Decreto-Lei n. $136 / 2014$

de 9 de setembro

REGIME JURÍDICO DA URBANIZAÇÃO E EDIFICAÇÃO(RJUE)

CAPÍTULO V Taxas inerentes às operações urbanísticas

Artigo 116.ㅇ

Taxa pela realização, manutenção e reforço de infraestruturas urbanísticas

(Revogado)

Artigo 116.ㅇ

Pagamento da Mais-Valia Urbanística

1 - A mais-valia é devida no momento imediatamente a seguir à aprovação do planeamento de pormenor ou, no caso de não existir planeamento de 
pormenor, após a aprovação da operação urbanística, momento que procede o início do processo de urbanização:

2 - A mais-valia deve estar integralmente paga antes que as obras de urbanização se iniciem.

3 - O pagamento pode ser faseado, a pedido do proprietário/promotor, sendo que a sua completa liquidação deve ocorrer antes de emitida qualquer autorização/licenciamento da edificação. $O$ pagamento inicial não pode ser inferior a $50 \%$ da mais-valia total e deve ser totalmente pago em dinheiro.

4 - A mais-valia pode ser paga em dinheiro ou em terrenos a integrar no património municipal, caso a autarquia aceite essa possibilidade. $O$ valor dos terrenos para pagamento da mais-valia não pode ultrapassar os vinte por cento do total da mais-valia devida. 